\title{
Discussion on the Urban Design Course Teaching Reform in Landscape Architecture Program
}

\author{
Binglu Wu \\ School of Architecture and Urban Planning, Shandong Jianzhu University, \\ Jinan 250000, Shandong Province
}

\begin{abstract}
In the landscape architecture planning and design, urban open space is one of the important research contents. However, in the process of constructing urban open space system, a study only relying on the open space is difficult to conduct. In the urban design course teaching, the ultimate goal of landscape architecture program is to promote students to get a comprehensive understanding of the urban design theories, skillfully command the urban framework and texture knowledge, and continuously improve the self-capability in creative design.
\end{abstract}

Keywords- Landscape Architecture Program; Urban Design; Course Teaching; Reform

\section{Introduction}

The design programs in architectural and forestry colleges and universities are always greatly different, especially different in terms of the urban design course teaching in the landscape architecture program. Therefore, it is necessary to actively explore the urban design course teaching system in the landscape architecture program and make innovations, so as to constantly train the students' capability in comprehensive analysis, investigation and research, and integrated analysis and so on. On this basis, innovation is also made in the actual teaching method, aiming to better optimize the urban design course teaching.

\section{The construction of basic urban design theory}

In the urban design theory teaching [1], urban design is mainly reflected from providing an effective bridge for the related designs. First, urban design is always throughout the study of the urban planning process. Second, there is a connection between urban design and architectural design, and also corresponding constraints are available for the design of the buildings. Third, in urban design, the public interests and well-being are more greatly emphasized; the key of the urban design lies in the public space of a city. Therefore, urban design is very closely related to landscape planning and design. The theory teaching of the urban design course in the landscape architecture program, therefore, should not only be confined to the urban open space, but also pays attention to the related theories and technologies of urban design and the important role of urban design theory in the urban weaving mechanism. Thus, students are helped to better accumulate theories in practice, and also effectively apply theories to the urban organizational texture and ultimately improve the theory literacy in terms of the overall and local aspects of urban design.

\section{Deeply understanding the complexity of urban areas and the public spaces}

In the urban design theory teaching process, the commercial cultural squares and the walking streets are practically researched and investigated, so that students are promoted to get a comprehensive understanding of the relationship 
of urban essence and public space with urban areas. The understanding of the complexity of the city center areas is necessarily especially understood, because business, entertainment, business and administration are usually integrated in these areas that can fully give an expression to the features and style of a city and are regarded as the keys in urban space. On this basis, the students can get a comprehensive understanding of the public space types and scales of urban areas and deeply analyze the effect of the urban environment and the buildings on the outer space function and form design aspects. In the meantime, the students also need to fully understand the concept of public space and the characteristics of spatial hierarchy and constantly strengthen their own ability to analyze the urban public space, and have a proficient command of the expressive ways and the most basic elements in the urban public space design process [2]. In addition, teachers must actively guide the students to correctly understand the place spirit and attach importance to the urban space construction methods, for the purpose of promoting the students to better transform space into place.

\section{The urban design course system innovation}

In the urban design course teaching, the urban landscape planning and design course is the most critical. However, the course is emphatically oriented at the students studying in the landscape architecture program, and therefore its actual teaching is different from the course design in architectural schools.

\subsection{Stage teaching}

The ultimate goal of the urban design course teaching is to positively improve the students' competence in comprehensive analysis and space design and so on. For the urban design oriented at agriculture and forestry, the teaching contents impartation and the specific methods of expressing urban design are necessarily enhanced in the aspect of teaching arrangement. The urban design course teaching can be divided into four stages, mainly including the introduction of the professional basic knowledge, analyzing site investigation, generating design scheme, and expressing design concept [3]. Students can improve their capability in design innovation and also exercise the thinking ideas about design after the four stages of learning.

\subsection{The introduction of the knowledge}

In the process of urban design, the effective control of the public space is often implemented to finish the design, thus promoting the healthy development of the urban space to some extent. Excellent urban design can not only improve the living environment of people, but also can make cities better develop toward a pleasant direction. In the early stages of the urban design, the issues such as the rational utilization of land and the renewal of urban areas are stressed. In the later development, however, the people's awareness in the environmental project is enhanced. For this reason, in the process of urban design, the important role of landscape ecological environment and open space is gradually reflected, and a broad development platform is available for the theory and practice combination of landscape architecture with urban design to some extent. In the urban design course teaching, the key for the landscape architecture program is to actively introduce the urban design concepts related to space and scale by starting from the relevant knowledge of landscape architecture, discuss the similarities and differences between landscape design and urban design through comparative methods, and then positively guide students to build a better cognitive system for the fundamentals of urban design.

\subsection{Dominated by landscape}

In the second stage of the course teaching, field research work is necessarily implemented, so that the students are promoted to train the rational analysis ideas about urban design. On this basis, teachers must properly guide the students to 
recognize and deeply think about landscape environment and site ecological aspects, and then promote them to preliminarily be aware of the aspects such as urban space and environment. In the generation of urban design, the weak capability of the students in the program to generate an architectural space is necessarily focused: architectural form design can be appropriately weakened and also converted to urban landscape architecture reshaping and open space system for positively guiding the students and ultimately accomplishing the perfect modelling of urban space [4].

\section{The optimization and innovation of the urban design course teaching method in landscape architecture program}

At present, the urban design course in the landscape architecture program is not enough, so it is very difficult to achieve a specific teaching goal in the limited course teaching process. Therefore, in the actual teaching process, a scientific and reasonable teaching system and the rationality of teaching methods are necessary.

\subsection{Group collaboration}

Learning tasks can be completed with good quality under the collaboration between the classmates. The students in a class can be divided into 10 11 groups; the number of the students in each group is about 3; each group is required to carry out the researches on different fields and finally make a summary in order to acquire the comprehensive site research results.

\subsection{Role transition}

The achievements gained in the researches are shared, so as to better improve the students' learning initiative and promote them to understand the learning contents deeply. However, the smooth work of the students in other groups in the later design is directly related to the actual research results, making it easier to promote the relationship between the class groups. Meanwhile, the traditional model of education is necessarily changed in the achievement report; the students in each group are required to report the stage results in front of the whole class and then exchange and discuss with each other using the group discussion platform to actively put forward relevant suggestions and demands. The students, who have pressures in learning, can be motivated to continue to study hard.

\subsection{Providing proper instruction}

When archives are segmented and deepened, bottlenecks are easy to emerge, and thus, teachers need to provide students with the necessary perfect demonstrations and help them to better understand the design essentials and methods and attain a further development [5].

\subsection{Implementing full expression}

Teachers should encourage students to fully show their own design results using the diversified expressive ways. That is to say, students are allowed to make use of design drawings, PPT, and even entity modeling and computer modeling methods for showing their design results. In the process of teaching, teachers should constantly strengthen the use of different software and display the design results using the software, so that students are subtly influenced and positively guided to learn and use the related computer design software tools in the designing process.

\subsection{Carrying out the inspection regularly}

Urban design is the focus of the landscape architecture courses, and therefore, the role of the performance appraisal is very important. The main goal of the course teaching is to cultivate the students' innovation capability; the performance in this course is mainly divided into daily performance and final test results, and the result in the process of research is also used. On this basis, team scoring method is demanded, in order to better cultivate the students' teamwork spirit. 


\section{Conclusion}

To sum up, urban design was incorporated into the professional teaching in the 1990s, but constantly develops and receives new ideas as an urban planning and design course. However, the urban design course was offered by agriculture and forestry colleges and universities after the landscape architecture program was adjusted, and therefore, the professional knowledge background and the course offering practice are different from the course teaching in architecture schools. It is necessary to actively create and improve news teaching methods. In the urban design course teaching in the landscape architecture program, the course teaching arrangement is placed under the background of professional knowledge, in order to actively look for the major teaching methods and means proper for the students' learning and train the composite personnel demanded by the society. At present, the urban design course teaching reform in the landscape architecture program is at the exploration stage, so its specific teaching contents still need further development in systemic and practical aspects.

\section{References}

[1] Ting Da. Study on the Urban Design Course Teaching Optimization in Landscape Architecture Program-Beijing Forestry
University Is Taken for Example [C]. The Collection of the Papers at the Chinese Society of Landscape Architecture, 2010: 665-668.

[2] Jie Zhu. Exploration and Study on the Urban Design Course Teaching Model in Landscape Architecture Program [J]. Journal of the Western Living Environment, 2015 (4): $15 \sim 17$.

[3] Yu Jin, Gang Wang, Zhi Zhang, et al. Study on the "Studio" Teaching Model in Landscape Architecture Program [J]. Journal of Anhui Agricultural Sciences, 2015 (12): 321-322, 333.

[4] Yanbin Pan. Discussion on the Garden Botany Course Reform in the Landscape Architecture Program of Art Colleges - the Landscape Architecture Program of Hubei Academy of Fine Arts Is Taken for Example [J]. Journal of Green Science and Technology, 2015 (5): 323-324, 328.

[5] Yiting Wang. Study on the Garden Architectural Design Course Teaching Reform in Landscape Architecture Program - the Landscape Architecture Program of Chongqing Normal University Is Taken for Example [J]. Journal of College Education, 2015 (3): 130-131. 